\title{
Short communication: To what extent do environmental or technological conditions affect the sensory differentiation of raw ewe milk cheeses produced in valley or mountain farms?
}

\author{
Gustavo Amores, (ㄱ) Francisco José Pérez-Elortondo, (1) Marta Albisu, (i) and Luis Javier R. Barron* (i) \\ Lactiker Research Group, Faculty of Pharmacy, University of the Basque Country (UPV/EHU), Paseo de la Universidad 7, 01006 Vitoria-Gasteiz, \\ Spain
}

\begin{abstract}
This work discusses the extent to which differences in technological or environmental conditions affect the sensory properties of cheeses made in mountain or valley farms. The work is focused on Idiazabal cheese, frequently made with lamb rennet paste and with milk from sheep flocks managed under extensive grazing systems. Fourteen sensory attributes were assessed, and free fatty acid content and rennet lipase activity were analyzed in cheeses from mountain and valley farms. Sensory differences between cheeses were mainly dependent on the type and amount of rennet used for cheesemaking, particularly on the level of rennet lipase activity. The sensory attributes did not appear to be influenced by pasture type, grazing practices, or environmental conditions associated with farm location. Rennet lipase activity was responsible for the high scores of strong sensory attributes such as pungent mouthfeel, and these attributes masked the potential sensory differences that could be found due to farm location.
\end{abstract}

Key words: sensory properties, rennet lipase, sheep cheese, extensive grazing

\section{Short Communication}

Raw milk properties, together with cheesemaking and ripening conditions used in the dairy farm, will be decisive for cheese sensory profiles. Recently, animal feeding has gained interest regarding cheeses produced with milk from grazing animals due to their nutritional and sensory properties (Morand-Fehr et al., 2007; Bravo-Lamas et al., 2018), and this is the case for many mountain cheeses in Europe (Santini et al., 2013). Regarding raw milk properties, the effects of the feeding system, botanical composition of the pasture,

Received February 13, 2020.

Accepted August 13, 2020.

*Corresponding author: luisjavier.rbarron@ehu.eus and grazing management on the sensory properties of mountain cheeses has been reported (Coppa et al., 2011; Esposito et al., 2014; Aprea et al., 2016). In general, more intense fruity, floral, and vegetal flavors, and lower buttery, toasty, and creamy flavors, have been reported in cheeses derived from mountain grazing than from animals grazing in valleys or fed concentrate and forage (Bugaud et al., 2001; Carpino et al., 2004; Valdivielso et al., 2016). However, a recent review of factors influencing the flavor of cheeses made with milk from different feeding regimens concluded that the influence of the animal diet is unclear because many potential factors are involved at farm level and during cheesemaking and ripening (Kilcawley et al., 2018). In this regard, some authors have reported that changes in cheesemaking technological conditions were more determinant of sensory properties than whether cheeses were made in mountain or valley farms (Cornu et al., 2009; Rusco et al., 2017).

The objective of this work was to identify specific differences in odor, taste, and mouthfeel attributes of raw sheep milk cheeses from mountain and valley extensivegrazing farming. The work discusses the extent to which differences in the technological or environmental conditions affect the sensory properties of valley and mountain cheeses.

Six artisanal dairy farms belonging to the Idiazabal Protected Denomination of Origin (PDO) cheese designation participated in this study. Three farms were located in the mountains (M1, M2, and M3; altitude $700-1,200 \mathrm{~m}$ ) and the other three in the surrounding valleys (V1, V2, and V3; altitude 100-400 m) of the Aralar Natural Park (Basque Country, Spain). Sheep flocks' sizes were between 150 and 440 lactating ewes, and the flocks were managed under extensive grazing from late spring onward. Detailed information about localization, climate conditions, pasture characteristics, and flock management of the commercial sheep flocks has been previously described (Bravo-Lamas et al., 2018). Cheeses were manufactured according to PDO Idiazabal guidelines (Ministerio de Agricultura, Pesca 
Table 1. Definition and composition of odor references used for Idiazabal cheese sensory panel training and evaluation of samples ${ }^{1}$

\begin{tabular}{|c|c|c|c|c|c|}
\hline Attribute & Definition & Low-intensity reference & Score & High-intensity reference & Score \\
\hline Hay & Aroma associated with hay & $0.15 \mathrm{~g}$ hay $/ 30 \mathrm{~g}$ of curd & 3 & $1 \mathrm{~g}$ hay $/ 30 \mathrm{~g}$ of curd & 9 \\
\hline Aromatic herbs & $\begin{array}{l}\text { Aroma associated with aromatic } \\
\text { plants }\end{array}$ & $0.1 \mathrm{~g}$ thyme $/ 30 \mathrm{~g}$ of curd & 3 & $0.8 \mathrm{~g}$ thyme $/ 30 \mathrm{~g}$ of curd & 9 \\
\hline
\end{tabular}

${ }^{1}$ Other odor, taste, and mouthfeel references as previously described in Valdivielso et al. (2016).

y Alimentación, 1993), using automatic vats and controlled ripening chambers in valley farms and nonautomatic vats and ripening chambers without control of temperature and relative humidity in mountain farms. All shepherds except one used artisanal lamb rennet pastes for cheesemaking. These pastes were produced by the shepherds by mixing minced lamb stomachs with salt according to the procedure previously described by Bustamante et al. (2000). Cheeses were semi-hard and cylindrically shaped and weighed approximately $1.5 \mathrm{~kg}$ after 4 mo of ripening. At this time, cheeses from vats produced on 2 different days of the third week of June were collected in each farm. Three whole cheeses per vat were randomly sampled. Two cheeses were used for physicochemical analysis $(\mathrm{n}=24)$, and the other was used for sensory analysis $(\mathrm{n}=12)$. In addition, samples $(\sim 20 \mathrm{~g})$ of artisanal lamb rennet pastes and commercial liquid lamb rennet were collected from the farms.

A trained panel of 10 assessors ( 6 women and 4 men, aged from 25 to 50 years) evaluated the cheese samples. Five panelists belonged to the PDO Idiazabal official sensory panel, and all assessors had participated in a previous study on valley and mountain cheeses with 13 training sessions (Valdivielso et al., 2016). For the current study, the assessors received 7 training sessions of between 60 and 90 min each. In the first training session, the sensory references were discussed. In the next 4 sessions, the references were presented, together with cheese samples, and new attributes and scaled reference scores were established. The last 2 training sessions were used to assess cheese samples without references, with subsequent results harmonization within the panel. Eight odor and 6 taste and mouthfeel sensory attributes were assessed using a $10-\mathrm{cm}$ unstructured scale. Definition and composition of odor, taste, and mouthfeel for low- and high-intensity references used for cheese sample evaluation were previously described (Valdivielso et al., 2016), except for nutty, hay, grass, aromatic herbs, and natural rennet odor. For these attributes, new definition and sensory references were developed for training and evaluation of the cheese samples (Table 1$)$. Cheeses were kept $\left(3-4^{\circ} \mathrm{C}\right)$ in the laboratory until sensory analysis. Cheeses were tempered at $17 \pm 2^{\circ} \mathrm{C}$, and rind-free coded samples, each with a 3 -digit number, were randomly presented in parallelograms of approximately $1.5 \mathrm{~cm}$ high, $1.5 \mathrm{~cm}$ wide, and $7 \mathrm{~cm}$ long. Low-mineralization water and Granny Smith apple were used to remove any aftertaste between samples. Sensory assessments were conducted in individual booths of $20 \pm 2^{\circ} \mathrm{C}$ at the sensory laboratory, which complied with international standards of test rooms (ISO, 2007). In each session, the assessors analyzed all the cheese samples once, and before the sample evaluations, a harmonization session was conducted. Two sessions within the same week (6 samples per session) were used to evaluate the cheese samples in duplicate.

Free fatty acid (FFA) contents of the cheese samples were analyzed in duplicate by gas chromatography, as described previously by Chávarri et al. (1997), using a free fatty acid phase (Agilent Technologies Inc., Madrid, Spain) capillary column (25 m long, $0.32 \mathrm{~mm}$ internal diameter, $0.50 \mu \mathrm{m}$ film thickness) installed in a 7890 Series II gas chromatograph (Agilent Technologies) equipped with a flame ionization detector. Concentrations of FFA were expressed as micromoles per $100 \mathrm{~g}$ of cheese. Additionally, the lipase activity was determined in triplicate in artisanal lamb rennet pastes and commercial liquid lamb rennet, as previously described (Hernández et al., 2005). Lipase activity was expressed in international lipase units (ILU) per gram of rennet.

Statistical analysis of data was performed using IBM SPSS version 25.0 (IBM, Armonk, NY). The general linear model (GLM) of ANOVA was applied to investigate the effect of farm location (valley, mountain) on the FFA content and sensory scores of cheese samples using the following model: $Y_{i j}=\mu+L_{i}+F_{j}\left(L_{i}\right)+\varepsilon_{i j}$, where $Y_{i j}=$ dependent variables; $\mu=$ intercept; $L_{i}=$ farm location fixed effect; $F_{j}=$ flock fixed effect; and $\varepsilon_{i j}$ $=$ random residual effects. For the analysis of sensory scores, the panelist and session terms, together with the interaction term, were included in the model as random 
and fixed effects, respectively. Subsequently, an analogous GLM was applied to investigate the effect of level of rennet lipase activity (low, high) on the FFA content of cheese samples. In addition, principal component (PC) analysis was performed to study the relationships between FFA content and sensory characteristics of the cheeses. Statistical significance was declared at $P \leq$ 0.05 .

The results corresponding to scores for sensory attributes measured in valley and mountain cheeses are shown in Figure 1. Most odor, taste, and mouthfeel attributes were significantly $(P \leq 0.05)$ different between mountain and valley cheeses, with higher scores for overall intensity, rennet, and hay odor, acid and bitter taste, and pungent and persistence mouthfeel in mountain than in valley cheeses, and the opposite for toasty odor and sweet taste. Despite the significant differences observed for hay odor, this attribute showed very low scores $(<2)$ in both valley and mountain cheeses, as did other nonsignificant attributes such as grass, nutty, and aromatic herbs odors (Figure 1). Overall, these results indicated that the flavor of mountain cheeses was stronger than that of valley cheeses, most likely due to rennet and pungent attributes, whereas valley cheeses showed milder flavor characterized by sweet and toasty notes. However, the effect of individual flock was statistically significant $(P \leq 0.05)$ for most cheese sensory properties (data not shown) and was particularly relevant for mountain farms, as shown in Figure 2A. Figure 2 depicts sensory variable loadings and farm distribution in the first $2 \mathrm{PC}$ dimensions and, whereas the valley farms (V1, V2, and V3) are grouped on the left side of PC1, M2 and M3 mountain farms are grouped on the right side of PC1, and M1 is located next to the valley farms. Even when valley farms were compared with farm M1, no significant differences $(P>0.05)$ were found in the cheese sensory attributes, with the exception only of persistence mouthfeel, which showed a slightly higher score $(\sim 0.5)$ in the M1 mountain farm. In this regard, the changes in environmental, flock management, and grazing conditions due to farm altitude seemed to be insufficient to explain differences in the sensory properties of valley and mountain cheeses. Thus, particular changes in the cheesemaking conditions could be decisive to generate the strong flavors of the M2 and M3 cheeses compared with those of M1 and valley cheeses.

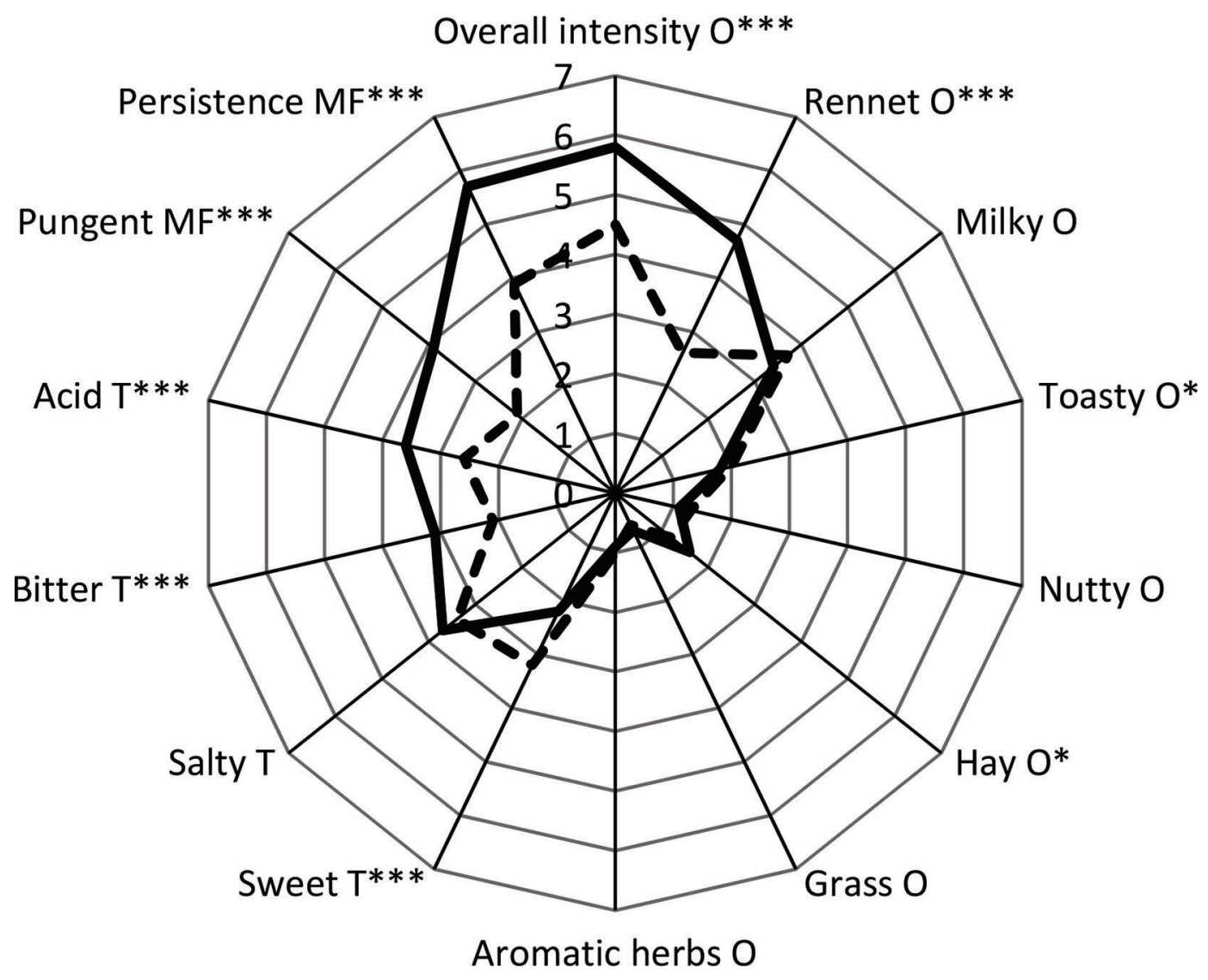

Figure 1. Spider plot depicting scores (mean values) for odor, taste, and mouthfeel attributes of Idiazabal cheeses made in valley (solid line) and mountain (dashed line) farms after $120 \mathrm{~d}$ of ripening. $\mathrm{MF}=$ mouthfeel; $\mathrm{O}=$ odor; $\mathrm{T}=$ taste. ${ }^{*} P \leq 0.05 ;{ }^{* * *} P \leq 0.001$. 

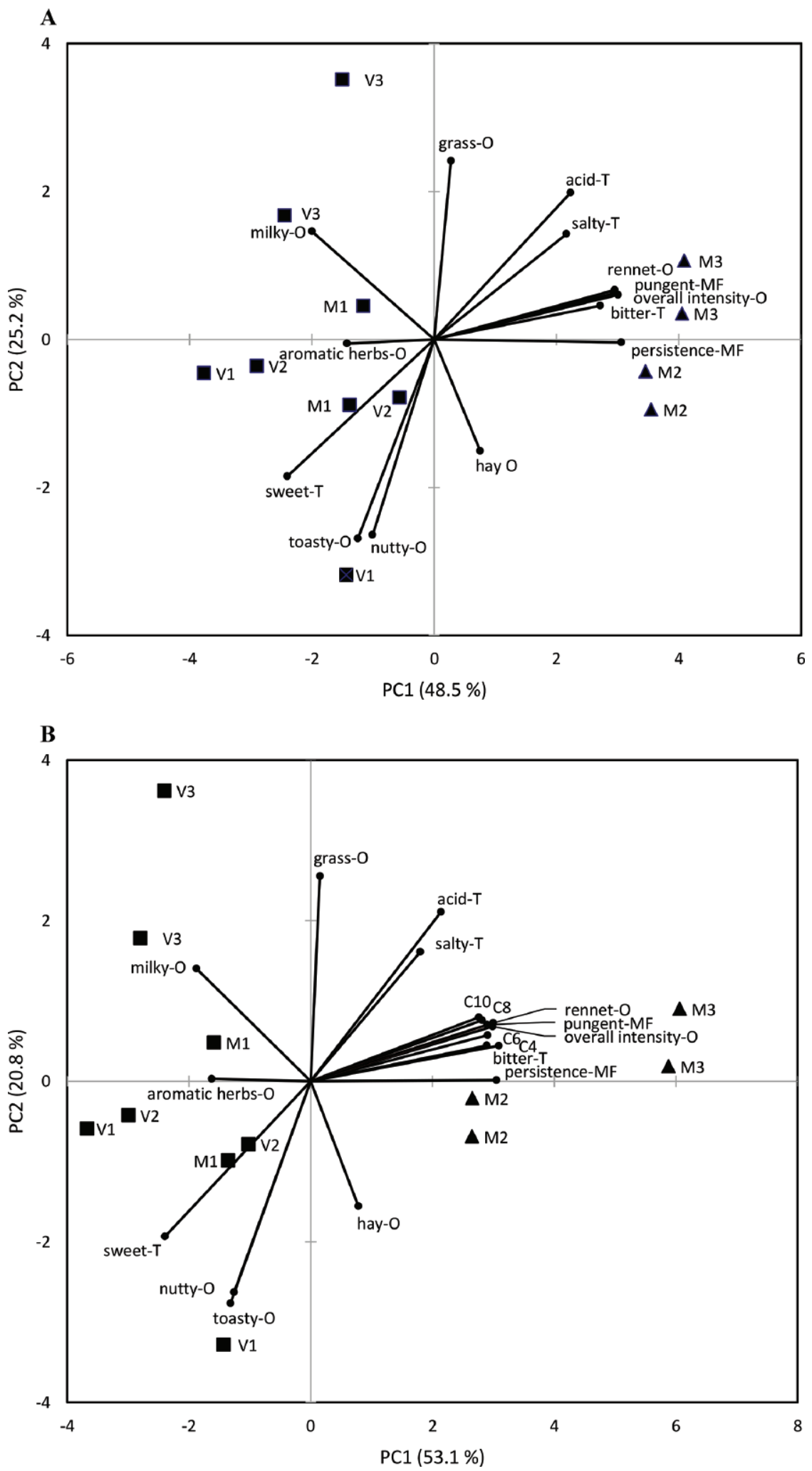

Figure 2. Biplot depicting variable loadings and sample distribution in the first 2 dimensions derived from principal component (PC) analysis including sensory attributes (A) and, separately, short-chain free fatty acid content and sensory attributes (B) of the 120-d ripened Idiazabal cheeses from valley (V) and mountain (M) farms. Farm codes (V or M) correspond with those in Table 2 . $=$ Cheeses with low level $[<35$ international lipase units (ILU)/50 L of milk] of rennet lipase activity; $\boldsymbol{\Delta}=$ cheeses with high level (>170 ILU/50 L of milk) of rennet lipase activity; $\mathrm{C} 4=$ butyric acid; $\mathrm{C} 6=$ caproic acid; $\mathrm{C} 8=$ caprylic acid; $\mathrm{C} 10=$ capric acid; $\mathrm{MF}=$ mouthfeel; $\mathrm{O}=$ odor; $\mathrm{T}=$ taste. 
Table 2. Lipase activity of rennets used for cheesemaking in valley (V) and mountain (M) farms, and total content of free fatty acids (FFA) in Idiazabal cheeses ripened for $120 \mathrm{~d}$

\begin{tabular}{|c|c|c|c|c|}
\hline Farm type & Lamb rennet type & $\begin{array}{c}\text { Rennet lipase } \\
\operatorname{activity}^{1} \text { (ILU/g) }\end{array}$ & $\begin{array}{l}\text { Lipase activity added } \\
\text { to milk vat (ILU/50 L) }\end{array}$ & $\begin{array}{l}\text { Total FFA content }{ }^{1} \\
\quad(\mu \mathrm{mol} / 100 \mathrm{~g})\end{array}$ \\
\hline \multicolumn{5}{|l|}{ Valley } \\
\hline V3 & Commercial liquid & $2.17 \pm 0.04$ & 32.5 & $476 \times 10^{1} \pm 236$ \\
\hline \multicolumn{5}{|l|}{ Mountain } \\
\hline M1 & Artisanal paste & $2.66 \pm 0.11$ & 30.0 & $355 \times 10^{1} \pm 553$ \\
\hline
\end{tabular}

${ }^{1}$ Mean $\pm \mathrm{SD} ; \mathrm{ILU}=$ international lipase units.

In addition to differences in the facilities and ripening chambers between valley and mountain farms, rennet type and the amount of rennet added per liter of milk could be strongly related to these results. Previous studies have demonstrated that use of lamb rennet pastes is related to the development of rennet odor and pungent mouthfeel during cheese ripening, which is of particular relevance for the typical flavor of Idiazabal PDO cheese (Hernández et al., 2005, 2009).

Table 2 shows the lipase activity of rennets and levels used for cheesemaking in the valley and mountain farms. Regardless of the rennet type (artisanal or commercial), valley farms and farm M1 used lower levels of rennet lipase activity (less than $35 \mathrm{ILU} / 50 \mathrm{~L}$ of milk) compared with the levels (higher than $170 \mathrm{ILU} / 50 \mathrm{~L}$ of milk) used by cheesemakers in farms M2 and M3. In addition, the total FFA content of cheese was between 1.3 and 4.7 times higher in M2 and M3 farms, respectively, compared with the farms using low levels of rennet lipase activity (Table 2). Regarding cheese FFA profiles, Table 3 shows the individual FFA contents of the cheese samples, taking into account the rennet lipase activity added to milk vat by cheesemakers. As observed, except for acetic and propanoic acids, the contents of most individual FFA were higher $(P \leq$ $0.05)$ in cheeses made with high than with low levels of rennet lipase activity. In particular, the content of those short-chain FFA released mainly by rennet lipase

Table 3. Free fatty acid (FFA) content $(\mu \mathrm{mol} / 100 \mathrm{~g})$ in 120-d ripened Idiazabal cheeses made with low $(<35$ ILU/50 L of milk) and high (>170 ILU/50 L of milk) levels of rennet lipase activity ${ }^{1}$

\begin{tabular}{|c|c|c|c|}
\hline Fatty acid & Low level & High level & $P$-value \\
\hline Acetic acid & $108 \times 10^{1} \pm 371$ & $989 \pm 278$ & NS \\
\hline Propanoic acid & $86.2 \pm 19.0$ & $78.7 \pm 20.9$ & NS \\
\hline Butyric acid & $845 \pm 154$ & $386 \times 10^{1} \pm 155 \times 10^{1}$ & $* * *$ \\
\hline Isovaleric acid & $6.10 \pm 4.60$ & $9.44 \pm 2.73$ & $* * *$ \\
\hline Caproic acid & $267 \pm 70$ & $118 \times 10^{1} \pm 659$ & $* * *$ \\
\hline Enanthic acid & $3.13 \pm 1.36$ & $7.26 \pm 4.76$ & $* * *$ \\
\hline Caprylic acid & $97.0 \pm 27.5$ & $439 \pm 274$ & $* * *$ \\
\hline Capric acid & $218 \pm 70$ & $103 \times 10^{1} \pm 688$ & $* * *$ \\
\hline Undecanoic acid & $2.00 \pm 0.94$ & $8.96 \pm 6.57$ & $* * *$ \\
\hline Lauric acid & $101 \pm 33$ & $423 \pm 268$ & $* * *$ \\
\hline Tridecanoic acid & $2.99 \pm 1.15$ & $7.51 \pm 4.12$ & $* * *$ \\
\hline Myristic acid & $133 \pm 40$ & $453 \pm 268$ & $* * *$ \\
\hline Pentadecanoic acid & $13.7 \pm 4.3$ & $42.0 \pm 20.5$ & $* * *$ \\
\hline Palmitic acid & $252 \pm 83$ & $712 \pm 333$ & $* * *$ \\
\hline Palmitoleic acid & $11.9 \pm 3.7$ & $25.8 \pm 11.0$ & $* * *$ \\
\hline Stearic acid & $57.8 \pm 22.4$ & $117 \pm 33$ & $* * *$ \\
\hline Oleic acid & $244 \pm 91$ & $484 \pm 139$ & $* * *$ \\
\hline$\alpha$-Linoleic acid & $18.7 \pm 7.4$ & $39.3 \pm 12.6$ & $* * *$ \\
\hline$\alpha$-Linolenic acid & $13.2 \pm 6.2$ & $58.0 \pm 29.2$ & $* * *$ \\
\hline Short-chain FFA & $260 \times 10^{1} \pm 615$ & $759 \times 10^{1} \pm 298 \times 10^{1}$ & $* * *$ \\
\hline Medium-chain FFA & $252 \pm 76$ & $935 \pm 540$ & $* * *$ \\
\hline Long-chain FFA & $598 \pm 208$ & $144 \times 10^{1} \pm 555$ & $* * *$ \\
\hline Saturated FFA & $316 \times 10^{1} \pm 725$ & $935 \times 10^{1} \pm 387 \times 10^{1}$ & $* * *$ \\
\hline Unsaturated FFA & $288 \pm 108$ & $607 \pm 190$ & $* * *$ \\
\hline Total FFA & $345 \times 10^{1} \pm 759$ & $996 \times 10^{1} \pm 405 \times 10^{1}$ & $* * *$ \\
\hline
\end{tabular}

${ }^{1}$ Values presented as means $\pm \mathrm{SD} ; \mathrm{NS}=$ not significant $(P>0.05)$; ILU $=$ international lipase units. $* * * P \leq 0.001$. 
action (FFA from 4 to 10 carbon atoms; Bustamante et al., 2000) were strongly higher in cheeses made with high lipase activity. For both low and high levels, the percentage of total short-chain FFA was around $75 \%$, whereas the percentage of short-chain FFA from 4 to 10 carbon atoms was $33 \%$ and $66 \%$ for cheeses made with low and high rennet lipase activity, respectively. These results confirmed that the pregastric esterase contained in the rennet released preferentially short-chain fatty acids esterified at the sn-3 position of the triacylglycerol molecules (Collins et al., 2003). Furthermore, as previously mentioned, acetic and propanoic acid content did not differ between cheeses made with low and high levels of rennet lipase activity. These volatile FFA mainly originate through other biochemical pathways, from lactate and citrate by lactic acid bacteria, by propionibacteria or molds, or by catabolism of amino acids (McSweeney and Sousa, 2000).

Finally, a new PC analysis was conducted, including the sensory attributes and the main short-chain FFA released by rennet lipase activity during the ripening of cheeses (Figure 2B). As expected, strong sensory attributes, such as overall intensity and rennet odor, and pungent and persistence mouthfeel, were highly positively correlated with butyric, caproic, caprylic, and capric acids. On the other hand, these short-chain FFA were negatively correlated with milder sensory attributes such as milky, toasty, and nutty odors and sweet taste. As previously observed for Figure 2A, the cheeses were not grouped by the farm type (valley or mountain) but according to the level of rennet lipase activity used for cheesemaking.

In conclusion, the sensory characteristics of Idiazabal PDO cheeses made in both valley and mountain farms were mainly dependent on the type and amount of rennet used for cheesemaking, particularly on the level of rennet lipase activity added to the milk vat. This rennet lipase activity definitively determined the high scores for overall intensity and rennet odor, and for pungent and persistence mouthfeel in the cheeses. In general, odor, taste, and mouthfeel attributes of Idiazabal cheeses did not appear to be influenced by pasture type, grazing practices, and environmental conditions associated with farm location (valley or mountain), but cheese sensory profile was strongly marked by rennet lipase addition. These results indicated that potential sensory differences between valley and mountain cheeses that could be found due to farm altitude, grazing, or environmental conditions were subtle enough to be masked by the use of lipolytic rennets. In this regard, it could be advisable to control the lipase activity of the artisanal rennet pastes often used by cheesemakers, to prescribe adequate rennet levels that would permit regulatory boards, producers, and consumers to iden- tify and characterize the typical sensory properties of Idiazabal cheeses produced in mountains or in valleys.

\section{ACKNOWLEDGMENTS}

The authors thank the shepherds of Enirio-Aralar Commonwealth, Spain. Financial support was provided by the Spanish (AGL2013-48361-C2-R; Madrid, Spain) and Basque (IT944-16) Governments (Vitoria-Gasteiz, Spain). The authors have not stated any conflicts of interest.

\section{REFERENCES}

Aprea, E., A. Romanzin, M. Corazzin, S. Favotto, E. Betta, F. Gasperi, and S. Bovolenta. 2016. Effects of grazing cow diet on volatile compounds as well as physicochemical and sensory characteristics of 12 month-ripened Montasio cheese. J. Dairy Sci. 99:6180-6190. https://doi.org/10.3168/jds.2016-10929.

Bravo-Lamas, L., N. Aldai, J. K. G. Kramer, and L. J. R. Barron. 2018. Case study using commercial dairy sheep flocks: Comparison of the fat nutritional quality of milk produced in mountain and valley farms. Lebensm. Wiss. Technol. 89:374-380. https:// doi.org/10.1016/j.lwt.2017.11.004.

Bugaud, C., S. Buchin, A. Hauwuy, and J. B. Coulon. 2001. Relationships between flavour and chemical composition of Abondance cheese derived from different types of pastures. Lait 81:757-773. https://doi.org/10.1051/lait:2001162.

Bustamante, M., F. Chávarri, A. Santisteban, G. Ceballos, I. Hernández, M. J. Miguélez, I. Aranburu, L. J. R. Barron, M. Virto, and M. de Renobales. 2000. Coagulating and lipolitic activities of artisanal lamb rennet pastes. J. Dairy Res. 67:393-402. https://doi .org/10.1017/S0022029900004350.

Carpino, S., J. Horne, C. Melilli, G. Licitra, D. M. Barbano, and P. J. Van Soest. 2004. Contribution of native pasture to the sensory properties of Ragusano cheese. J. Dairy Sci. 87:308-315. https:// doi.org/10.3168/jds.S0022-0302(04)73169-0.

Chávarri, F., M. Virto, C. Martín, A. I. Nájera, A. Santisteban, L. J. R. Barron, and M. de Renobales. 1997. Determination of free fatty acids in cheese: Comparison of two analytical methods. J. Dairy Res. 64:445-452. https://doi.org/10.1017/S0022029997002197.

Collins, Y. F., P. L. H. Mc Sweeney, and M. G. Wilkinson. 2003. Lipolysis and free fatty acid catabolism in cheese: A review of current knowledge. Int. Dairy J. 13:841-866. https://doi.org/10.1016/ S0958-6946(03)00109-2.

Coppa, M., I. Verdier-Metz, A. Ferlay, P. Pradel, R. Didienne, A. Farruggia, M. C. Montel, and B. Martin. 2011. Effect of different grazing systems on upland pastures compared with hay diet on cheese sensory properties evaluated at different ripening times. Int. Dairy J. 21:815-822. https://doi.org/10.1016/j.idairyj.2011.04.006.

Cornu, A., N. Rabiau, N. Kondjoyan, I. Verdier-Metz, P. Pradel, P. Tournayre, J. Berdagué, and B. Martin. 2009. Odour-active compound profiles in Cantal-type cheese: Effect of cow diet, milk pasteurization and cheese ripening. Int. Dairy J. 19:588-594. https:// doi.org/10.1016/j.idairyj.2009.04.008.

Esposito, G., F. Masucci, F. Napolitano, A. Braghieri, R. Romano, N. Manzo, and A. Di Francia. 2014. Fatty acid and sensory profiles of Caciocavallo cheese as affected by management system. J. Dairy Sci. 97:1918-1928. https://doi.org/10.3168/jds.2013-7292.

Hernández, I., L. J. R. Barron, M. Virto, F. J. Pérez-Elortondo, C. Flanagan, U. Rozas, A. I. Nájera, M. Albisu, M. S. Vicente, and M. de Renobales. 2009. Lipolysis, proteolysis, and sensory properties of ewe's raw milk cheese (Idiazabal) made with lipase addition. Food Chem. 116:158-166. https://doi.org/10.1016/j.foodchem .2009.02.026.

Hernández, I., M. de Renobales, M. Virto, F. J. Pérez-Elortondo, L. J. R. Barron, C. Flanagan, and M. Albisu. 2005. Assessment of 
industrial lipases for flavour development in commercial Idiazabal (ewe's raw milk) cheese. Enzyme Microb. Technol. 36:870-879. https://doi.org/10.1016/j.enzmictec.2004.12.032.

ISO. 2007. General guidance for the design of test room. Standard no. 8589:2007. International Organization for Standardization, Geneva, Switzerland.

Kilcawley, K. N., H. Faulkner, H. J. Clarke, M. G. O'Sullivan, and J. P. Kerry. 2018. Factors influencing the flavour of bovine milk and cheese from grass based versus non-grass based milk production systems. Foods 7:37. https://doi.org/10.3390/foods7030037.

McSweeney, P. L. H., and M. J. Sousa. 2000. Biochemical pathways for the production of flavour compounds in cheeses during ripening: A review. Lait 80:293-324. https://doi.org/10.1051/lait:2000127.

Ministerio de Agricultura, Pesca y Alimentación. 1993. Reglamento de la Denominación de Origen Idiazabal y de su Consejo Regulador. Bol. Of. Estado 289:34591.

Morand-Fehr, P., V. Fedele, M. Decandia, and Y. Le-Frileux. 2007. Influence of farming and feeding systems on composition and quality of goat and sheep milk. Small Rumin. Res. 68:20-34. https:// doi.org/10.1016/j.smallrumres.2006.09.019.

Rusco, G., A. Natale, C. Palermo, S. Chessa, D. Nardiello, A. M. Caroli, D. Centonze, A. Di Luccia, and B. la Gatta. 2017. Charac- terization of Silter cheeses produced in valley and alpine pastures by a proteomic approach. J. Adv. Dairy Res. 5:183.

Santini, F., F. Guri, and S. Gómez y Paloma. 2013. Labelling of agricultural and food products of mountain farming. JCR Scientific and Policy Reports. Publication Office of the European Union, Luxembourg.

Valdivielso, I., M. Albisu, M. de Renobales, and L. J. R. Barron. 2016. Changes in the volatile composition and sensory properties of cheeses made with milk from commercial sheep flocks managed indoors, part-time grazing in valley, and extensive mountain grazing. Int. Dairy J. 53:29-36. https://doi.org/10.1016/j.idairyj.2015 .09.007.

\section{ORCIDS}

Gustavo Amores @i https://orcid.org/0000-0002-9512-7682

Francisco José Pérez-Elortondo (1) https://orcid.org/0000-0002-5207 $-4883$

Marta Albisu (i) https://orcid.org/0000-0002-4724-9757

Luis Javier R. Barron (ㄱ https://orcid.org/0000-0002-2563-1082 